\title{
ANÁLISE DA PRODUÇÃO CIENTTÍFICA SOBRE FORMAÇÃO DE PROFESSORES: REALIDADE E POSSIBILIDADES NA ÁREA DA EDUCAÇÃO FÍSICA
}

Análisis de la producción científica sobre formación de profesores: realidad y posibilidades en el área de la Educación Física

Analysis of scientific production of teacher formation: reality and possibilities in the area of Physical Education

Márcia Morschbacher*

Melina Silva Alves **

Raquel Cruz Freire Rodrigues ***

https://doi.org/10.38117/2675-181X.formov2020.v2i2n4.497-519

\section{RESUMO}

O presente trabalho analisa a produção científica voltada à formação de professores em teses e dissertações na área da Educação Física, referente ao período de 2014-2019. O levantamento das produções ocorreu na Biblioteca Digital Brasileira de Teses e Dissertações. Realizou-se a análise a partir das categorias: concepção de formação de professores; concepção de formação de professores de Educação Física; referência à Resolução n. 02/2015 e à Associação Nacional pela Formação dos Profissionais da Educação (Anfope). Evidenciamos que a produção científica analisada se alicerça, hegemonicamente, nas pedagogias do aprender a aprender e na formação em Educação Física dividida entre licenciatura e bacharelado. Por outro lado, encontramos trabalhos fundamentados na concepção de formação omnilateral e na proposição de Licenciatura Ampliada para a formação única em Educação Física. Quanto à Resolução n. 02/2015 e à Anfope, poucos são os trabalhos que as têm como referência.

PALAVRAS-CHAVES: Produção do Conhecimento; Formação de Professores; Educação Física.

\section{RESUMEN}

El presente trabajo analiza la producción científica orientada a la formación de profesores en tesis y disertaciones en el área de la Educación Física, referente al período 2014-2019. El levantamiento de las producciones ocurrió en la Biblioteca Digital Brasileña de Tesis y Disertaciones. Se realizó el análisis a partir de las categorías: concepción de formación de profesores; concepción de formación de profesores de Educación Física; referencia a 
ANÁLISE DA PRODUÇÃO CIENTÍFICA SOBRE FORMAÇÃO DE PROFESSORES:

Realidade e possibilidades na área da Educação Física

la Resolución n. 02/2015 y a la Asociación Nacional por la Formación de Profesionales de la Educación (Anfope). Evidenciamos que la producción científica analizada se basa hegemónicamente en las pedagogías del aprender a aprender y en la formación en Educación Física dividida entre licenciatura y bachillerato. Sin embargo, encontramos trabajos fundamentados en la concepción de formación omnilateral y en la propuesta de licenciatura ampliada para la formación única en Educación Física. En cuanto a la Resolución n. 02/2015 y a Anfope, pocos trabajos tienen como referencia.

PALABRAS CLAVES: Producción del Conocimiento; Formación de Profesores; Educación Física.

\section{ABSTRACT}

This paper analyzes the scientific production on teacher education found in theses and dissertations in the field of Physical Education, within 2014-2019. The production survey took place at the Brazilian Digital Library of Theses and Dissertations. The analysis was carried out from the categories: concept of teacher education; concept of Physical Education teacher education; Resolution no. 02/2015 and the National Association for the Formation of Education Professionals (Anfope). We show that the scientific production analyzed is hegemonically based on the pedagogies of learning to learn and on Physical Education formation divided between teaching degree and bachelor's degrees. On the other hand, we found works based on the concept of omnilateral formation and on the proposal of an Extended Teaching Degree for a unified formation in Physical Education. Regarding the Resolution no. 02/2015 and Anfope, there are few works having them as a reference.

KEYWORDS: Knowledge Production; Teachers Education; Physical Education.

\section{Introdução}

Neste artigo, analisamos teses e dissertações da área da Educação Física voltadas à investigação da formação de professores e concluídas entre 2014 e 2019. Esta pesquisa responde à necessidade de identificar e compreender as principais tendências dessa produção científica.

Utilizamos como referência teórico-metodológica para a realização da pesquisa 0 materialismo histórico dialético, expresso no movimento de ascensão do abstrato ao concreto e sintetizados por Kosik (2002) ${ }^{1}$ na compreensão de três graus: 1) Apropriação

\footnotetext{
${ }^{1} \mathrm{O}$ movimento de ascensão do abstrato ao concreto não é espontâneo, os fenômenos não se dão a conhecer de imediato, é necessário desenvolver ferramentas de pensamento para superar a aparência do objeto, na busca de sua essência. Para Kosik (2002) é possível superar a pseudoconcreticidade de um objeto através do movimento da pesquisa que parte de uma caótica representação inicial para alçar uma multiplicidade
} 
profunda da matéria; 2) Análise de cada forma de desenvolvimento do material; 3) Investigação da coerência interna. Ademais, as referências da concepção de formação humana omnilateral (MANACORDA, 1991), da pedagogia histórico-crítica (MARTINS, 2010; SAVIANI, 2006), da base comum nacional para a formação de professores (BRZEZINSKI, 2011) e da licenciatura ampliada (TAFFAREL; SANTOS JUNIOR, 2010) foram empregadas como aporte teórico da investigação.

Foi realizada a busca da produção na Biblioteca Digital Brasileira de Teses e Dissertações (BDTD) ${ }^{2}$ durante o mês de outubro de 2019 utilizando os termos: "Formação Inicial" e "Educação Física"; "Formação de Professores" e "Educação Física"; "Formação Profissional" e "Educação Física". Foram descartadas do banco de dados, após a leitura dos títulos, resumos e conclusões, as produções científicas que não se relacionavam com o objeto de estudo. A produção foi classificada e analisada considerando três biênios: 2014-2015/2016-2017/2018-2019.

Destacamos este período por reconhecermos o debate das Diretrizes Curriculares Nacionais para a Formação Inicial em Nível Superior e para a Formação Continuada (Resolução CNE/CP 02/2015), que vai da discussão e sua aprovação, até os reflexos nas teses e dissertações voltadas à formação de professores. Também levamos em consideração o debate sobre a concepção de formação de professores em geral e, em específico, de Educação Física (neste caso, o debate entre a proposta de Licenciatura Ampliada para a formação única em Educação Física e a formação dividida entre licenciatura e bacharelado), assim como a referência à Anfope.

Fizemos a opção da Anfope por se tratar de uma entidade científica que tem se posicionado contrária às diretrizes que o Governo Federal apresentou em 2019 ao Conselho Nacional de Educação, as Diretrizes Curriculares para Formação Inicial de Professores da Educação Básica e a Base Nacional Comum para a Formação Inicial de Professores da Educação Básica (BNC-Formação) - Resolução CNE/CP 02/2019. Estas Diretrizes não apresentam o caráter democrático de construção coletiva realizada na elaboração da Resolução CNE/CP 02/2015. Atualmente, entidades científicas, sindicatos, movimentos sociais e pesquisadores vêm rechaçando a BNC-Formação tanto pelo seu

de determinações e relações - síntese de múltiplas determinações - expressão de sua totalidade concreta. Utilizamos, contingenciados pelo método, a técnica de análise de conteúdo para categorização dos dados levantados no campo empírico de análise, no entanto, o método de pesquisa foi quem possibilitou, através do movimento da abstração, levantar as regularidades, tendências e singularidades desta análise da produção do conhecimento que doravante expõe-se no formato de artigo científico.

${ }^{2}$ A BDTD foi desenvolvida e é coordenada pelo Instituto Brasileiro de Informação em Ciência e Tecnologia (IBICT). Integra os sistemas de informação de teses e dissertações provenientes de instituições de ensino e pesquisa no Brasil. Disponível em: 〈http://bdtd.ibict.br/vufind/>. 
ANÁLISE DA PRODUÇÃO CIENTÍFICA SOBRE FORMAÇÃO DE PROFESSORES:

Realidade e possibilidades na área da Educação Física

conteúdo quanto pela forma em que foi construída sem dialogar amplamente com a sociedade civil.

As questões que orientaram a seleção de categorias utilizadas como guias da análise de conteúdo foram: Quais as concepções de formação de professores e de formação de professores de Educação Física apresentam-se como hegemônicas na área? Quais as contribuições da Anfope em tais produções? Como a Resolução CNE/CP 02/2015 apresenta-se nas produções? Destarte, as categorias foram: Concepção de formação de professores; Concepção de formação de professores de Educação Física; Referência à Anfope; Referência à Resolução CNE/CP 02/2015.

A hipótese: estudos anteriores da Educação Física no campo da análise de Projetos Políticos Pedagógicos (ALVES, 2015), da formação científica (MORSCHBACHER, 2016) e da Prática de Ensino/Estágio Supervisionado (RODRIGUES, 2014) demonstram que há uma disputa pela direção da formação na área, que se expressa na relação singularparticular-universal: ou seja na relação dialética entre a Formação Ampliada em Educação Física versus divisão entre licenciatura e bacharelado (singular); a concepção de formação de professores - base comum nacional da Anfope versus professor reflexivo (pedagogias do aprender a aprender, epistemologia da prática, etc.) (particular) e; a referência da formação humana omnilateral versus unilateral (universal).

Neste sentido, a concepção de formação de professores - aqui ressaltamos a importância da Resolução CNE/CP 02/2015 no avanço em direção a uma base comum nacional para a formação de professores no país - realiza a mediação (particular) entre a concepção mais geral de formação humana (universal) e a singularidade da formação nas licenciaturas específicas, no caso deste estudo, a Educação Física.

\section{Análise das Teses e Dissertações concluídas no período de 2014 a 2019}

A seguir, apresentamos as regularidades extraídas do objeto, a saber, teses e dissertações da área da Educação Física voltadas à investigação da formação de professores e concluídas entre 2014 e 2019, tendo em conta os biênios - 2014/2015, 2016/2017 e 2018/2019 - e as categorias de análise ${ }^{3}$ - concepção de formação de professores, concepção de formação de professores de Educação Física, e as referências à Resolução 02/2015 e à Anfope.

\footnotetext{
${ }^{3}$ Devido ao elevado número de teses e dissertações analisadas, a seção de Referências apresenta somente as produções científicas citadas ao longo do texto com a finalidade de expressar as tendências evidenciadas em cada categoria de análise.
} 


\section{I- As produções entre 2014-2015}

Utilizando os parâmetros de busca, localizamos 177 trabalhos concluídos em 2014 e 2015, dos quais selecionou-se 52 trabalhos - 36 dissertações e 16 teses.

\section{A) Concepção de formação de professores}

Reconhecemos, no debate sobre formação de professores, duas grandes tendências: a concepção derivada das pedagogias do aprender a aprender ${ }^{4}$ e a concepção fundada na omnilateralidade. $\mathrm{Na}$ análise realizada buscamos evidenciar a presença e o modo como se expressam estas tendências na produção científica.

As pedagogias do aprender a aprender predominam nos trabalhos analisados vinte e nove produções (55,76\% - vinte e duas dissertações e sete teses). Encontramos as seguintes referências sobre a formação de professores: a) processo de construção de conhecimento no cotidiano escolar; b) processo de constituição da subjetividade e das identidades - remetendo-se, em geral, à autoformação; c) saberes docentes; d) professor reflexivo e; e) desenvolvimento de competências.

Caracterizadas, entre outros aspectos, pela supervalorização do cotidiano, do imediatamente acessível como parâmetro a ser privilegiado no trabalho educativo, as pedagogias do aprender a aprender preterem as formas historicamente elaboradas do conhecimento e consideram-no um "recurso cognitivo para adaptação do indivíduo ao meio" (MARTINS, 2012, p. 58). É nesta direção que o cotidiano (escolar) é a principal referência para a formação de professores, espaço no qual esta deve ocorrer a partir da construção do conhecimento pela resolução de problemas imediatos (MARTINS, 2012). Como expressão desta tendência, destacamos o trabalho de Silva (2014, p. 8), que afirma:

[...] pensar a prática como lócus de formação implica em considerar que parte do trabalho que os professores de Educação Física realizam dentro de seu espaço profissional é aprendido na e para a prática a partir da experiência de ensino por eles desenvolvidas, dando embasamento para uma epistemologia da prática profissional.

No entanto, para Martins (2012, p. 59):

Na relação de condicionabilidade da construção do conhecimento ao meio, observa-se que este, ou por outra, os contextos, são apresentados como se guardassem para todos os indivíduos as mesmas possibilidades

\footnotetext{
${ }^{4}$ Conforme Duarte (2001), podem ser agrupadas no interior do universo pedagógico denominado "pedagogias do aprender a aprender": o construtivismo, a perspectiva da epistemologia da prática, do professor reflexivo etc. $\mathrm{O}$ autor, ainda, identifica relações entre as pedagogias do aprender a aprender e o universo ideológico neoliberal e pós-moderno.
} 
ANÁLISE DA PRODUÇÃO CIENTÍFICA SOBRE FORMAÇÃO DE PROFESSORES:

Realidade e possibilidades na área da Educação Física

humanizadoras, escamoteando e naturalizando as desigualdades instituídas pela organização social capitalista [...].

A captação imediata da realidade não assegura o seu conhecimento nas suas múltiplas determinações - ou seja, a realidade necessita ser explicada e, neste aspecto, situa-se a teoria e, portanto, a transmissão e apropriação dos conhecimentos historicamente produzidos como elementos imprescindíveis a partir dos quais "esta realidade passa a ser conhecida, compreendida e problematizada em sua essência" (MARTINS, 2012, p. 60).

Outro aspecto a ser destacado é a compreensão da formação de professores como processo individual e/ou intersubjetivo de constituição da subjetividade e da identidade profissional. Nesta questão, destacamos Melo (2015, p. 153), que afirma que:

Mas outras experiências vão nos compondo como docentes, se
constituem como marcas que serão relembradas nos momentos de
pensar sobre a profissão e de fazer a vida. A presente pesquisa surge
com intencionalidades simples, mas se desenvolve como um percurso
de conhecimento de si e de busca pela formação que acontece em
conjunto, no reconhecimento da produção da docência como uma
profissão coletiva.

Tem-se, neste entendimento, a separação entre a subjetividade (e/ou da identidade) da totalidade histórico-social, o que inviabiliza a sua apreensão como síntese de múltiplas determinações e em unidade dialética com a base material da sociedade (MARTINS, 2015). Trata-se da compreensão e explicação de ambas as categorias de forma idealista, porque apartada das condições materiais de existência, e subjetivista, porque desconsidera as determinações destas condições e a unidade dialética entre humanização e alienação no capitalismo.

Como expressão da concepção de formação de professores fundada na omnilateralidade, encontramos seis trabalhos (três teses e três dissertações - 11,54\%). Estes estudos, balizados pelo materialismo histórico-dialético, defendem a possibilidade, nas atuais condições objetivas, de formar professores com base no enfrentamento ao rebaixamento da formação da classe trabalhadora e na articulação entre a formação humana e o projeto histórico socialista. Sobre esse aspecto, Alves (2015, p. 8) afirma que:

[...] apresentamos como objetivo contribuir teoricamente para o desenvolvimento de uma tendência de formação de professores de Educação Física cujo lastro formativo se opusesse diametralmente ao processo de produção e reprodução do capital e que contivesse em si parâmetros teórico-metodológicos capazes de contribuir com a necessidade de transição de modo de produção e reprodução da vida. 
Estes trabalhos referenciam o papel fundamental dos conhecimentos historicamente produzidos para a formação de professores, na perspectiva de que estes sejam formados com a partir de em uma consistente base teórica e que os problemas presentes na formação sejam superados (como a separação entre teoria e prática).

Encontramos, ainda, catorze trabalhos (nove dissertações e cinco teses - 26,93\%) que se utilizam de diferentes referenciais teóricos abordar a formação de professores caracterizada genericamente como "crítica" (a partir de autores da Educação Física, da Educação ou das Ciências Sociais). Além disso, três trabalhos (5,77\%) não explicitaram a concepção de formação de professores que fundamentou a pesquisa.

\section{B) Concepção de formação de professores de Educação Física}

Nesta categoria, ao analisar a produção científica selecionada, evidenciamos duas tendências: a naturalização da formação dividida entre licenciatura e bacharelado e a defesa da Licenciatura Ampliada 5 .

No primeiro item, registramos duas expressões dessa tendência: 1) a ausência do debate sobre a divisão da formação, ou seja, as pesquisas abordam seus objetos sem referência a esta questão e; 2) defesa explícita da divisão da formação entre licenciatura e bacharelado.

Evidenciamos quarenta e quatro trabalhos $(84,61 \%)$ no período de $2014 / 2015$ trinta e uma dissertações e treze teses - que têm como tendência a naturalização do debate sobre a formação de professores na área, provavelmente, na perspectiva de que a divisão da formação é uma condição dada.

Encontramos duas dissertações caracterizadas pela defesa explícita da formação dividida - 3,85\%. À guisa de exemplo, destacamos a justificação desta divisão a partir da Resolução CNE/CES 07/2004 e da afirmação da possibilidade de sua "apropriação crítica no processo de formação para o trabalho em Educação Física” (PEREIRA, 2014, p. 153).

Sobre a Licenciatura Ampliada, identificamos seis trabalhos (três teses e três dissertações - 11,54\%). Estes abordam o debate sobre a base teórica a fundamentar esta

\footnotetext{
${ }^{5} \mathrm{O}$ principal argumento sobre a defesa da divisão da formação baseia-se na afirmação da distinção entre os campos de trabalho escolar (aos licenciados) e não escolar (aos bacharéis) como critério para a criação de dois cursos de graduação. No outro polo, tem-se a proposta da Licenciatura Ampliada, que sustenta que a formação de professores de Educação Física deve ocorrer em um curso único, tendo em vista que o trabalho pedagógico é o elemento que confere identidade aos professores da área nos diversos campos de trabalho (TAFFAREL; SANTOS JÚNIOR, 2010).
} 
ANÁLISE DA PRODUÇÃO CIENTÍFICA SOBRE FORMAÇÃO DE PROFESSORES:

Realidade e possibilidades na área da Educação Física

proposta $^{6}$, o desenvolvimento de parâmetros teórico-metodológicos e o trato com o conhecimento dos conteúdos da cultura corporal e da Prática de Ensino.

Estes trabalhos apresentam a Licenciatura Ampliada como proposta superadora à formação de professores de Educação Física fundada no projeto hegemônico de formação - pautado no princípio da simetria invertida, na negação de conhecimentos, na submissão ao mercado de trabalho e na formação dividida. Nesse sentido, Alves (2015, p. 8) evidencia que:

Concluímos que tais parâmetros teórico-metodológicos encontram referência na defesa do projeto histórico de sociedade socialista, da concepção de formação omnilateral, da docência como central ao projeto de formação de professores, da licenciatura ampliada como forma mais avançada de organização do projeto de formação em Educação Física, do método dialético como necessidade para o trato com o conhecimento clássico, da unidade metodológica como necessária para dar coesão ao trabalho do coletivo de professores, da cultura corporal como objeto de estudo mais avançado para a explicação da realidade e do desenvolvimento do pensamento teórico e da autodireção como fundamentais ao desenvolvimento da compreensão dos trabalhadores enquanto classe para si.

Estes trabalhos relacionam, ainda, a proposta da Licenciatura Ampliada na especificidade da formação de professores de Educação Física com a omnilateralidade e com o projeto histórico superador da sociedade de classes.

\section{C) Referência à Resolução CNE/CP 02/2015}

Apenas dois trabalhos (uma tese e uma dissertação, ambas de 2015) mencionam a Resolução CNE/CP n. 02/2015, o que corresponde a 3,84\% das produções analisadas. Em parte, podemos atribuir esta evidência ao período de produção das teses e dissertações e à data publicação do documento legal - ressaltando-se que vinte e cinco trabalhos (ou 48,06\%) foram concluídos em 2014. Ambos os trabalhos que mencionam a Resolução CNE/CP n. 02/2015 informam a data de sua aprovação (01 de julho de 2015) e o prazo de dois anos para a adaptação curricular pelos cursos de licenciatura. Não encontramos sinalizações para a análise da resolução.

\section{D) Referência à Anfope}

Nesta categoria, localizamos nove trabalhos (quatro dissertações e quatro teses 17,30\%). Os demais não realizam mencionam a Anfope (quarenta e três estudos ou

\footnotetext{
${ }^{6} \mathrm{O}$ materialismo histórico-dialético, a psicologia histórico-cultural, a pedagogia histórico-crítica e a abordagem crítico-superadora da Educação Física.
} 
82,69\%). Este é um dado preocupante, dada a relevância da Associação no debate acadêmico, científico e político sobre a formação de professores.

Nestes nove trabalhos, a base comum nacional da Anfope é a principal referência adotada - o que se evidencia em cinco trabalhos (três dissertações e duas teses). Destacamos, ainda, a sua articulação (em duas teses e duas dissertações) com a Licenciatura Ampliada e com a concepção omnilateral e o projeto histórico socialista. À guisa de exemplo, Roseane Rodrigues (2014) e Alves (2015) destacam que a base nacional comum contribui para a elevação da capacidade teórica dos estudantes dos cursos de licenciatura e possibilita avançar no debate sobre a concepção de Licenciatura Ampliada.

Os demais (quatro trabalhos - uma dissertação e três teses) mencionam a Anfope na apresentação da trajetória histórica da formação de professores no Brasil, como base para a crítica às concepções tecnicistas de formação de professores, na seção de Referências e entidade presente em reunião do Fórum das Licenciaturas Ampliadas realizada em 2013 em Salvador/BA.

\section{II-As produções entre 2016-2017}

No período de 2016 e 2017 foram localizados 197 trabalhos. Selecionamos para a análise, 46 pesquisas, 23 teses e 21 dissertações. Foram descartadas as pesquisas que não se relacionavam com o objeto em debate.

\section{A) Concepção de formação de professores}

Localizamos nas pesquisas uma produção majoritária que agrupamos sob o eixo da concepção de formação do professor reflexivo ${ }^{7}$. Tal perspectiva apresentou-se em onze teses e treze dissertações $(52,17 \%)$, isto é, expressa-se hegemonicamente a relativização da função social do professor no processo de formação nas novas gerações, já que a centralidade formativa desta perspectiva se localiza no pragmatismo, na supervalorização do cotidiano e da pseudoconcreticidade, no recuo da teoria, na negação das metanarrativas e dos conhecimentos clássicos e universais e no descarte da objetividade, da verdade e da racionalidade.

A concepção do professor reflexivo apresenta na essência a necessidade de cada professor construir o seu próprio conhecimento para resolver os problemas que emergem

\footnotetext{
${ }^{7}$ Foram agrupadas: a referência construtivista, as pedagogias do "aprender a aprender" e as perspectivas de "construção dos saberes docentes" que tomam como referência as experiências advindas do meio empírico-cotidiano.
} 
ANÁLISE DA PRODUÇÃO CIENTÍFICA SOBRE FORMAÇÃO DE PROFESSORES:

Realidade e possibilidades na área da Educação Física

da prática imediata, o que, em última instância, significa adaptar-se à circunstância sem reconhecer radicalmente aquilo que a determina (MARTINS, 2010; 2015).

Três teses $(6,52 \%)$ foram desenvolvidas sob a referência da pós-modernidade. Duarte (2001, p. 87) ao criticar o construtivismo demonstra que o "construtivismo e o pós-modernismo pertencem a um mesmo universo ideológico e as interfaces entre ambos são tantas e em aspectos tão fundamentais que, em muitos momentos, não faz diferença caracterizar o pensamento de um autor como construtivista ou como pós-moderno".

A concepção de formação que advém da "agenda pós-moderna", declarada como "o surgimento de um novo paradigma" que "superou" a modernidade e as metanarrativas referencia-se em um descolamento das ideias de sua base real. Nesta corrente irracionalista, o sujeito histórico é fragmentado - perde seu caráter ontológico centrado na categoria trabalho em virtude da aparição de novas identidades, constituídas pelo discurso, pela linguagem, pelos olhares, pelas representações, isto é, perde-se qualquer referência teórica quanto à defesa de uma concepção formativa cuja referência seja universal e científica. No campo educacional, afirma Lavoura (2016, p. 207):

[...] tais teorizações pós-modernas acabam por carregar a ideia de que não há conhecimentos universais a serem transmitidos pela escola, criticando a comparação de conhecimentos e negando que um determinado conhecimento seja mais desenvolvido ou mais correto que o outro.

Uma tese apresentou como concepção formativa a referência de Theodor Adorno e uma dissertação a referência de formação com base na teoria comunicativa de Jürgen Habermas. Tais referências (4,34\%) pertencem à Escola de Frankfurt. Anderson (1976) reconhece nesta escola o denominado marxismo ocidental - no cerne desta perspectiva localiza-se o rompimento entre o marxismo e a causa política, entre a teoria e a prática, entre a ciência e programa.

Como primeira aproximação a uma síntese, pode-se afirmar que há uma tendência majoritariamente unilateral na produção (2016-2017) expressas nas concepções do professor reflexivo; na "agenda pós-moderna" e na Escola de Frankfurt.

Dez trabalhos, quatro dissertações e seis teses $(21,73 \%)$, apresentaram como referência a concepção de formação de professores pautada no marxismo. Destacam-se nestes trabalhos a defesa da omnilateralidade como concepção formativa. Como define Manacorda (1991, p. 81):

\footnotetext{
8 “"...] uma gama heterogênea e ampla de correntes de pensamento que possuem em comum uma atitude cética com relação à razão e às ciências modernas [...] que chega a negar a possibilidade de o capitalismo ser superado" (LAVOURA, 2016, p. 196).
} 
A omnilateralidade é, portanto, a chegada histórica do homem a uma totalidade de capacidades produtivas e, ao mesmo tempo, a uma totalidade de capacidades de consumo e prazeres, em que se deve considerar sobretudo o gozo daqueles bens espirituais, além dos materiais, e dos quais o trabalhador tem estado excluído em consequência da divisão do trabalho.

Embora minoritária, a referência marxista objetiva-se como contra tendência no âmbito da produção do conhecimento. Esta referência se coloca a la contra o projeto de formação do capital e de formação unilateral que se expressa, por exemplo, na referência do professor reflexivo. Alves e Santos Junior (2015) afirmam que as tendências de formação humana que se apresentam no modo capitalista de produção evidenciam o confronto de projetos de sociedade antagônicos - sendo a concepção unilateral enraizada no marco das relações capitalistas de produção e a concepção omnilateral fundada na possibilidade de desenvolvimento de uma sociedade socialista.

Por fim, destacamos que em seis dissertações e uma tese $(15,21 \%)$ não foi possível localizar referência a qualquer concepção sobre formação de professores (considerandose os elementos de análise) o que, pode indicar, a ausência de uma concepção formativa clara, e favorece, a perspectiva de formação unilateral - pois o conhecimento, como afirmado por Taffarel (2006) adquire força produtiva, política e ideológica, sendo portanto utópica uma pretensa neutralidade perante o embate entre projetos de formação diametralmente opostos.

\section{B) Concepção de formação de professores de Educação Física}

Em uma primeira instância, localizamos como referência à concepção de formação de professores de Educação Física o debate que envolve a questão formação em licenciatura versus formação em bacharelado versus formação em licenciatura ampliada. De forma distinta da formação em Licenciatura (restringe a atuação à Educação Básica) e da formação em bacharelado (para atuação nos demais campos de trabalho da Educação Física), a Formação em Licenciatura Ampliada objetiva a formação para a atuação nos diversos campos de trabalho sejam eles escolares ou não. Esta proposição formativa aproxima-se da tendência de um projeto de formação omnilateral, tomando como referência a Base Comum Nacional proposta pela Anfope. Sobre este embate, destaca-se como exemplo a afirmação de Morschbacher (2016, p. 205):

Com base no reconhecimento destes projetos em disputa e da necessidade vital da qualificação da formação da classe trabalhadora com vistas à explicação e intervenção mais concreta da realidade tendo em vista contribuir com a superação do modo de produção capitalista, é que entendemos que a Licenciatura Ampliada é o projeto mais avançado e com maiores condições de responder, do ponto de vista da formação dos professores de Educação Física, às necessidades destes 
trabalhadores no quadro da atual conjuntura de decomposição do modo de produzir e reproduzir a vida (de destruição das forças produtivas).

Considerando a importância do debate sobre as tendências formativas na área, localizamos na produção as seguintes perspectivas: a) não reconhecem a disputa da direção formação na área; b) reconhecem a disputa pela direção da formação, mas não se posicionam indicando proposição superadora - uma perspectiva crítico-reprodutivista (SAVIANI, 2006); c) reconhecem o debate e defendem a proposta formativa da Licenciatura Ampliada como mais avançada; d) não foi possível localizar a concepção de formação de professores de Educação Física.

Dos 46 trabalhos analisados, dezessete dissertações e dezesseis teses $(71,73 \%)$, não reconhecem o debate sobre a disputa da formação na área, apresentando em suas pesquisas ora a licenciatura como formação voltada para a atuação exclusiva na educação básica, ora o bacharelado na perspectiva da atuação em diferentes campos de atuação. Assim, permanece como cerne da questão o discurso que defende que a distinção entre licenciatura e bacharelado está na diferença entre os campos de atuação. Sobre isso, afirma Santos Junior (2005, p. 60-61):

Entre os argumentos utilizados, dantes como agora, para sustentar a proposta de fragmentação profissional entre Licenciatura e Bacharelado, encontramos o da diferença entre os locais de atuação profissional. Desconsidera-se, assim, que o que define determinada profissão são determinadas necessidades ou demandas sociais que podem ou não estar contempladas no processo de formação. Outro argumento sustentado é o de que o licenciado deveria ter predominantemente uma formação pedagógica, e o bacharel uma formação enfaticamente científica $-o$ que permitiu/permite interpretações equivocadas de que a formação pedagógica prescinde a ciência e vice-versa. Isto pode induzir, ainda, à consideração de que no âmbito da atuação do professor de educação física, no interior da escola, não se trata do conhecimento científico [...].

Uma dissertação e uma tese $(4,34 \%)$, embora apresentem o debate sobre a divisão da formação, não deixam clara a posição do pesquisador. Ribeiro (2016) reconhece e tece críticas ao processo de disputa na área, porém não indica proposição que supere a perspectiva de fragmentação da profissão, o que, provavelmente apareceria em suas conclusões.

Em quatro pesquisas, duas dissertações e duas teses $(8,69 \%)$, não foi possível reconhecer um debate mínimo sobre a concepção de formação de professores de Educação Física. O que pode indicar, uma pretensa neutralidade perante uma problemática candente, e que favorece, consequentemente, a perspectiva hegemônica. 
Por fim, apenas sete trabalhos, duas dissertações e cinco teses $(15,21 \%)$, apresentam como referência a Licenciatura Ampliada como proposta mais avançada para a formação na área. Ressaltamos que todas as sete pesquisas utilizaram como referencial teórico-metodológico o materialismo histórico dialético.

\section{C) Referência à Resolução CNE/CP 02/2015}

Sete teses e quatro dissertações $(23,91 \%)$ fizeram referência a Resolução CNE/CP $02 / 2015^{9}$. Quatro teses e duas dissertações $(13,04 \%)$ citam a resolução como indicação à legislação vigente para a área de Licenciatura. Três teses e duas dissertações $(10,86 \%)$, destacam a 02/2015 como uma resolução que qualifica nacionalmente os cursos de Licenciatura, na medida em que estes realizem as adequações para atender aos elementos por ela colocados. Uma tese utiliza-se da referência de Dourado (2015) para apresentar sua posição sobre a valorização da formação na $02 / 2015$.

\section{D) Referência à Anfope}

Seis teses e duas dissertações (17,39\%), apresentaram referência à Anfope. Três teses e duas dissertações $(10,86 \%)$ citam a Anfope junto a outras entidades que debatem a formação de professores. Uma tese $(2,17 \%)$ cita a Anfope através dos trabalhos de Brzezinski (2011), Raquel Rodrigues (2007; 2014) e Alves (2010). Um trabalho (2,17\%) cita a Anfope como referência ao conceito de formação continuada. Duas pesquisas (4,34\%), uma dissertação (SOUZA, 2017) e uma tese (MORSCHBACHER, 2016), utilizam a Anfope como referência à defesa de uma Base Comum Nacional para a formação de professores, e esta como fundamental para o desenvolvimento da proposta de Licenciatura Ampliada.

\section{III- As produções entre 2018-2019}

No período de 2018 e 2019, das teses e dissertações pesquisadas, foram computados 32 trabalhos, sendo 11 teses e 21 dissertações. Assim como nos demais períodos, foram descartados os trabalhos que, após a leitura dos títulos, resumos e conclusões, não se relacionavam minimamente com o objeto.

\section{A) Concepção de formação de professores}

Após filtragem, chegamos a um total de 11 teses. Neste âmbito, entre as concepções de formação de professores, observamos que existe um movimento bastante crescente na defesa aos Saberes Docentes, cinco trabalhos $(45,45 \%)$, e três trabalhos

\footnotetext{
${ }^{9}$ Todas as pesquisas analisadas foram defendidas durante a vigência desta Resolução.
} 
ANÁLISE DA PRODUÇÃO CIENTÍFICA SOBRE FORMAÇÃO DE PROFESSORES:

Realidade e possibilidades na área da Educação Física

$(27,27 \%)$ que tratam a formação a partir da perspectiva do Cotidiano. Estes trabalhos se destacam em trazer o docente como eixo da sua própria formação e o conhecimento construído pelo docente no seu fazer pedagógico.

Além destes, encontramos um trabalho $(9,09 \%)$ sobre a questão das narrativas orais/prática-reflexiva e um trabalho $(9,09 \%)$ baseado na teoria praxiológica em Bourdieu.

Em síntese, observamos que a maioria dos trabalhos possuem em maior ou menor grau a base na epistemologia da prática.

A epistemologia da prática tem como base a prática reflexiva e os saberes profissionais e representa uma determinada concepção de formação: possui sua fundamentação no cotidiano; no conhecimento assistemático; do professor enquanto mediador do processo da elaboração do conhecimento; a aprendizagem a partir de resolução de problemas e da atuação do professor pela prática reflexiva. Ou seja, "Sem dúvida, ao colocar em destaque o protagonismo do sujeito professor nos processos de mudanças e inovações, essa perspectiva pode gerar a supervalorização do professor como indivíduo" (PIMENTA, 2010, p. 22).

Apenas um trabalho $(9,09 \%)$ se diferencia dos demais, pois compreende a formação na defesa da "elevação do padrão cultural", entendendo que, para que ocorra a alteração da formação de professores, é necessário que eles tenham acesso ao conhecimento sistematizado que foi produzido pela humanidade e que deve ser tratado pedagogicamente na escola.

No caso das dissertações, foram destacados 21 trabalhos no total. No âmbito de concepção de formação de professores, foi observado seis trabalhos $(28,57 \%)$ que possuem a discussão acerca da formação de professores a partir da omnilateralidade, da psicologia histórico-cultural, da emancipação humana e da educação integral. Contudo, predomina a epistemologia da prática com nove trabalhos $(42,85 \%)$ relacionados com o professor pesquisar a sua própria prática, construção/fazer o próprio conhecimento, interformação/autoformação, saberes e competências docentes e do exercício profissional. Sobre a epistemologia da prática, identificamos que Backes (2018, p. 215) afirma que:

Assim, as implicações e desafios para a formação inicial concentramse na elaboração de estratégias que criem oportunidades para que os universitários identifiquem e reflitam sobre suas experiências prévias, sobre as crenças e conhecimentos que possuem, sobre a sua forma pessoal de pensar e agir no ensino dos esportes coletivos, e sua forma de construir seu próprio conhecimento sobre como ensinar. 
Outros seis trabalhos $(28,57 \%)$ compreendem a formação de professores de forma diversificada.

\section{B) Concepção de formação de professores de Educação Física}

Nas teses, encontramos uma diversificação do entendimento ou defesa do que seja Educação Física. Nos deparamos com um trabalho $(9,09 \%)$ destacando o Movimento corporal; um trabalho $(9,09 \%)$ - Sociocultural; um trabalho $(9,09 \%)$ - Prática corporal esportiva; um trabalho $(9,09 \%)$ - Pedagogia do esporte/cultura escolar do esporte; um trabalho (9,09\%) - Formação cultural; um trabalho (9,09\%) - Linguagens corporais/psicomotricidade; um trabalho $(9,09 \%)$ que compreende a Educação Física enquanto área de intervenção que se apropria das outras áreas da Ciências; um trabalho $(9,09 \%)$ - Cultura corporal/Educação Física plural; um trabalho $(9,09 \%)$ - abordagem Crítico-superadora.

Entre os trabalhos analisados, um trabalho (9,09\% apresentava o debate acerca da Licenciatura versus bacharelado e regulamentação da profissão e um trabalho $(9,09 \%)$ dialoga com a Educação Física com outras áreas de conhecimento, como ciências sociais e humanas, além da saúde coletiva, compreendendo a formação na perspectiva da formação mais ampliada, ao mesmo tempo que entende a Educação Física enquanto movimento corporal humano.

Nas dissertações, o campo da Educação Física foi possível destacarmos o debate da licenciatura ampliada e da fragmentação durante a formação em dois trabalhos (9,52\%), os quais defendem a formação ampliada, na perspectiva da abordagem da cultura corporal; e apenas um trabalho $(4,76 \%)$ entende que a Educação Física está relacionada com a atividade física seja na perspectiva da saúde individual ou da saúde coletiva. Aqui temos um movimento de dissertações que coloca no centro do debate a formação ampliada, cuja compreensão é a de que a formação deve ocorrer em um curso único e o professor de Educação Física atua em diversos campos de trabalho.

Foi observado que dois trabalhos $(9,52 \%)$ apresentam o trato com o conhecimento a ser desenvolvido nos cursos de licenciatura em Dança e na licenciatura em Educação Física, e outro trabalho trata a carreira e a formação profissional da Educação Física abordando o conteúdo dança.

Destaque-se que dois trabalhos $(9,52 \%)$ relacionam a contribuição da Educação Física com o letramento/letras-português. Nos chamou a atenção o fato de que são trabalhos que apresentam uma conotação de formação, que seria de formação ampliada, contudo afastam-se do objeto da Educação Física, enquanto área de conhecimento que deve ser tratado pedagogicamente os temas da cultura corporal: dança, jogos, esportes, ginástica, entre outros (COLETIVO DE AUTORES, 1992). 
ANÁLISE DA PRODUÇÃO CIENTÍFICA SOBRE FORMAÇÃO DE PROFESSORES:

Realidade e possibilidades na área da Educação Física

Outras temáticas foram versadas nas dissertações: um trabalho $(4,76 \%)$ - Cultura corporal e capoeira; um trabalho (4,76\%) - Cultura corporal e necessidades especiais; um trabalho (4,76\%) - Educação especial e Educação Física; um trabalho (4,76\%) que apresenta o debate acerca de Corpo/Corporeidade; um trabalho (4,76\%) - prática motora e esportes coletivos.

As demais dissertações, nove $(42,85 \%)$ apresentam como eixo a formação de professores em Educação Física.

\section{C) Referência à Resolução CNE/CP 02/2015}

O debate sobre a Resolução CNE/CP 02/2015 se apresentou em seis trabalhos $(54,54 \%)$ das teses. Apenas um trabalho $(9,09 \%)$ cita diretamente o artigo $3^{\circ}$ das diretrizes que trata sobre a educação a distância como modalidade formadora, e outra tese defende a educação inclusiva a partir da diversidade étnico-racial, de gênero, sexual, religiosa e faixa geracional. Em quatro teses $(36,36 \%)$ não foi identificada a Resolução $\mathrm{CNE} / \mathrm{CP}$ $02 / 2015$.

Nas dissertações, apenas cinco trabalhos $(23,80 \%)$ apresentam a Resolução CNE/CP 02/2015 e tratam de vários aspectos: a) no âmbito dos documentos oficiais; b) na defesa da modalidade presencial como lócus presencial; c) relativo à carga horária de estágio; d) à inclusão; e) e à defesa da necessidade de que a Educação Física se oriente pela Resolução CNE/CP 02/2015. As dissertações que foram selecionadas para análise tratam de formação inicial, de professores, profissional e, neste caso, o fato de, em sua maioria, dezesseis dissertações (76,19\%), não destacarem a Resolução CNE/CP 02/2015 é elemento bastante intrigante.

\section{D) Referência à Anfope}

Alguns elementos nos chamaram a atenção nesta categoria: das onze teses analisadas, o termo Anfope se fez presente em apenas duas teses (18,18\%). Registramos que a Anfope se configura como uma das entidades ${ }^{10}$ que vem defendendo a Resolução CNE/CP 02/2015, sendo contrária à BNC-Formação, defendida pelo Governo Federal. Isto porque, a BNC-Formação desconsidera os avanços construídos coletivamente por entidades científicas, sindicatos e movimentos sociais que se expressam na Resolução CNE/CP 02/2015.

Nas dissertações, dentre os vinte e um trabalhos que foram analisados, apenas um trabalho (4,76\%) cita a Anfope a partir da defesa da valorização e da profissionalização

\footnotetext{
${ }^{10}$ Disponível em: 〈http://www.anpae.org.br/website/noticias/483-em-defesa-da-res-022015>.
} 
dos educadores. Neste caso, as dissertações mantêm a regularidade das teses, em não destacar a Anfope no embate no campo da formação de professores.

\title{
Conclusões
}

No trabalho realizado, analisamos as produções científicas da área da Educação Física voltadas à formação de professores no período de 2014-2019, disponíveis na BDTD.

Inicialmente, constatamos que a formação de professores está direcionada, predominantemente, no entendimento da epistemologia da prática e, no plano mais geral, das pedagogias do aprender a aprender, perspectiva atualmente hegemônica como podemos observar nas análises dos trabalhos. Com menor incidência, a concepção da omnilateralidade também fundamenta as teses e dissertações.

$\mathrm{Na}$ formação de professores de Educação Física, percebemos um distanciamento do debate de formação na perspectiva da Licenciatura Ampliada, compreendida como a proposta de formação em que o professor de Educação Física possa desenvolver ferramentas teórico-metodológicas durante a sua formação inicial (graduação) independentemente do seu campo de atuação (escolar e não escolar).

Estes dados encontram correspondência com o estudo de Raquel Rodrigues (2014, p. 78), que afirma:

\begin{abstract}
Observamos que as produções destacadas possuem como referência, em maior ou menor grau, na epistemologia da prática, a pedagogia das competências, a fragmentação da formação do professor em Educação Física: licenciatura $\mathrm{x}$ bacharelado, os saberes docentes, entre outros. $\mathrm{O}$ que defendemos está na formação unificada de caráter ampliado para os professores de Educação Física; defendemos o conhecimento científico, construído pela humanidade e socializado na escola - local privilegiado para a sua transmissão; a Práxis pedagógica enquanto intervenção na realidade concreta e contraditória, o domínio das categorias centrais da docência e do trabalho pedagógico e, por fim, mas não menos importante, a formação humana amparada nas dimensões política/técnica/política/ filosófica.
\end{abstract}

Em relação à menção à Resolução CNE/CP 02/2015 e à Anfope, avaliamos que o volume de trabalhos poderia ser maior, pois o debate da formação de professores está em disputa e sindicatos, especialistas e entidades científicas vêm se posicionando em defesa deste documento legal. O fato da Anfope defender esta Resolução está articulado com as diretrizes curriculares da própria entidade: 
ANÁLISE DA PRODUÇÃO CIENTÍFICA SOBRE FORMAÇÃO DE PROFESSORES:

Realidade e possibilidades na área da Educação Física

- A formação para o humano, forma de manifestação da educação omnilateral dos homens;

- A docência como base da formação profissional de todos aqueles que se dedicam ao trabalho pedagógico;

- O trabalho pedagógico como foco formativo;

- A sólida formação teórica em todas as atividades curriculares, nos conteúdos específicos a serem ensinados pela educação básica e nos conteúdos especificamente pedagógicos;

- A ampla formação cultural;

- A criação de experiências curriculares que permitam o contato dos estudantes com a realidade da educação básica, desde o início do curso;

- A incorporação da pesquisa como princípio de formação;

-Possibilidade de vivência, pelos alunos, de formas de gestão democrática;

- O desenvolvimento do compromisso social e político da docência;

- A reflexão sobre a formação do professor e sobre suas condições de trabalho (BRZEZINSKI, 2011, p. 81).

No entanto, desde o golpe de 2016, seja com Temer, seja com Bolsonaro, a política educacional brasileira enfrenta reformas que visam atender às necessidades de um projeto assentado em princípios de aprofundamento da perspectiva unilateral de formação - em especial, considerando a formação de professores, dentro da lógica de formação do "professor reflexivo". Com a aprovação da Base Nacional Comum Curricular para a Educação Básica em 2017 (Resolução CNE/CP n. 2/2017) e 2018 (Resolução CNE/CP n. 4/2018), inicia-se, pelo CNE, o processo de revisão da Resolução CNE/CP 02/2015 que visa alinhar a política de formação de professores para a Educação Básica à BNCC. Assim, com a aprovação da Resolução CNE/CP n. 2/2019 - que revogou a Resolução CNE/CP 02/2015 - a Comissão Bicameral de Formação Inicial e Continuada de Professores do CNE, desprezou uma concepção importante construída pelo movimento dos educadores ao longo dos últimos 40 anos de luta, em defesa de uma política nacional de formação e valorização dos profissionais da educação.

Isto posto, é possível concluir, a partir desta análise sobre a produção do conhecimento de dissertações e teses (2014-2019), que o embate entre Formação Ampliada em Educação Física versus divisão entre licenciatura e bacharelado; a concepção de formação de professores - Base Comum Nacional Anfope versus professor reflexivo; e a referência da formação humana omnilateral versus unilateral, é expressão do real concreto no âmbito da produção das ideias, do conhecimento. Martins (2010; 2015), ao criticar proposições formativas construtivistas e pós-modernas, afirma que é preciso desenvolver-se um modelo alternativo de formação de professores que supere o 
modelo hegemônico cuja prática social tem demonstrado a imposição de uma realidade fetichizada e alienada.

Destarte, a nossa posição centra-se na defesa de que tal modelo alternativo apresenta a omnilateralidade como possibilidade de formação humana universal, a Base Comum Nacional da Anfope, a Resolução CNE/CP 02/2015 como referências para a formação de professores e a Licenciatura Ampliada como proposição mais avançada para a formação de professores de Educação Física. Destacamos ainda o método materialista histórico-dialético como referencial teórico mais avançado para se conhecer a realidade pois ele permite a distinção entre a aparência e essência do fenômeno, ou como expresso por Kosik (2002), a superação da pseudoconcreticidade - e apresenta como horizonte teleológico a necessária transição para um modo de produção e reprodução da vida para além do capital. Trata-se, portanto, da superação do capitalismo pelo socialismo, o que não se concretizará fora da ação humana e da luta de classes. Isso inclui, entre outras mediações, uma referência nacional para a formação de professores com a clareza teóricoprogramática deste projeto histórico que permite manter a unidade entre teoria revolucionária e prática revolucionária.

\section{Referências}

ALVES, Melina Silva. Divisão social do trabalho e alienação na formação de professores de Educação Física da UFS: o estágio supervisionado/prática de ensino enquanto síntese dialética dos projetos em disputa. 2010. 143f. Dissertação (Mestrado em Educação) - Núcleo de Pós-graduação em Educação, Universidade Federal de Sergipe, São Cristóvão, 2010.

Formação de professores e crise estrutural do capital: a necessidade histórica de uma formação para a transição de modo de produção e reprodução da vida. 2015. 349f. Tese (Doutorado em Educação) - Faculdade de Educação, Universidade Federal da Bahia, Salvador, 2015.

; SANTOS JUNIOR, Cláudio de Lira. Formação humana: a centralidade da contradição entre as relações de produção e o desenvolvimento das forças produtivas. Revista HISTEDBR On-line, Campinas, n. 65, p. 201-217, out. 2015.

ANDERSON, Perry. Considerações sobre o marxismo ocidental. Porto: Edições Afrontamento, 1976.

BACKES, Ana Flávia. O ensino dos esportes coletivos: um estudo na formação inicial em Educação Física. 2018. 266f. Dissertação (Mestrado em Educação Física) - Centro de Desportos, Universidade Federal de Santa Catarina, Florianópolis, 2018.

BRASIL. Resolução CNE/CES $n^{\circ}$ 7, de 31 de março de 2004. Institui as Diretrizes Curriculares Nacionais para os cursos de graduação em Educação Física, em nível 
ANÁLISE DA PRODUÇÃO CIENTÍFICA SOBRE FORMAÇÃO DE PROFESSORES:

Realidade e possibilidades na área da Educação Física

superior de graduação plena. Brasília, 2004. Disponível em: <http://portal.mec.gov.br/cne/arquivos/pdf/ces0704edfisica.pdf $>$. Acesso em: 30 jul. 2020.

BRASIL. Resolução CNE/CP $n^{o} 2$, de $1^{\circ}$ de julho de 2015. Define as Diretrizes Curriculares Nacionais para a formação inicial em nível superior (cursos de licenciatura, cursos de formação pedagógica para graduados e cursos de segunda licenciatura) e para a formação continuada. Brasília, 2015. Disponível em: <http://portal.mec.gov.br/docman/agosto-2017-pdf/70431-res-cne-cp-002-03072015pdf/file>. Acesso em: 30 jul. 2020.

. Resolução CNE/CP $n^{o} 2$, de 22 de dezembro de 2017. Institui e orienta a implantação da Base Nacional Comum Curricular, a ser respeitada obrigatoriamente ao longo das etapas e respectivas modalidades no âmbito da Educação Básica. Brasília, 2017. Disponível em: <http://basenacionalcomum.mec.gov.br/images/historico/ RESOLUCAOCNE_CP222DEDEZEMBRODE2017.pdf>. Acesso em: 30 jul. 2020.

Resolução CNE/CP $n^{o} 4$, de 17 de dezembro de 2018. Institui a Base Nacional Comum Curricular na Etapa do Ensino Médio (BNCC-EM), como etapa final da Educação Básica, nos termos do artigo 35 da LDB, completando o conjunto constituído pela BNCC da Educação Infantil e do Ensino Fundamental, com base na Resolução CNE/CP $n^{\circ}$ 2/2017, fundamentada no Parecer CNE/CP $n^{\circ}$ 15/2017. Brasília, 2018. Disponível em: < http://portal.mec.gov.br/docman/dezembro-2018-pdf/104101-rcp00418/file>. Acesso em: 30 jul. 2020.

Resolução CNE/CP $n^{o}$ 2, de 20 de dezembro de 2019. Define as Diretrizes Curriculares Nacionais para a Formação Inicial de Professores para a Educação Básica e institui a Base Nacional Comum para a Formação Inicial de Professores da Educação Básica (BNC-Formação). Brasília, 2019. Disponível em: 〈http://portal.mec.gov.br/docman/dezembro-2019-pdf/135951-rcp002-19/file>. Acesso em: 30 jul. 2020.

BRZEZINSKI, Iria. A ANFOPE e a definição de fundamentos e princípios para a formação de profissionais da educação: contribuições, atualizações, (re)definição de conceitos. In: BRZEZINSKI, I. (Coord.). ANFOPE em movimento 2008-2010. Brasília: Liber Livro; ANFOPE; CAPES, 2011. p. 78-132.

COLETIVO DE AUTORES. Metodologia do Ensino de Educação Física. São Paulo: Cortez, 1992.

DOURADO, Luiz Fernandes. Diretrizes Curriculares Nacionais para a Formação Inicial e Continuada dos Profissionais do Magistério da Educação Básica: concepções e desafios. Educação e Sociedade, Campinas, v. 36, n. 131, p. 299-324, abr./jun. 2015.

DUARTE, Newton. Vigotski e o "aprender a aprender": crítica às apropriações liberais e pós-modernas da teoria de Vigotski. Campinas: Autores Associados, 2001.

KOSIK, Karel. Dialética do concreto. Rio de Janeiro: Paz e Terra, 2002. 
LAVOURA, Tiago Nicola. O ceticismo epistemológico e a agenda pós-moderna: implicações para o trabalho educativo. Filosofia e Educação, Campinas, v. 8, n. 2, p. 194218, ago./set. 2016.

MANACORDA, Mario Alighiero. Marx e a pedagogia moderna. São Paulo: Cortez; Autores Associados, 1991.

MARTINS, Ligia Marcia. A formação social da personalidade do professor: um enfoque vygotskiano. 2.ed. Campinas: Autores Associados, 2015.

Da formação humana em Marx à pedagogia das competências. In: DUARTE, N. (Org.). Crítica ao fetichismo da individualidade. 2.ed.rev. Campinas: Autores Associados, 2012. p.47-64.

O legado do século XX para a formação de professores. In: MARTINS, L. M.; DUARTE, N. (Org.). Formação de professores: limites contemporâneos e alternativas necessárias. São Paulo: Cultura Acadêmica, 2010. p.13-31.

MELO, Tatiana Moraes Queiroz de. Experiências formativas no início da docência mediadas pelo PIBID Educação Física da Universidade Estadual de Feira de Santana, Bahia. 2015. 185f. Dissertação (Mestrado em Educação) - Centro de Educação, Universidade Federal do Espírito Santo, Vitória, 2015.

MORSCHBACHER, Márcia. Formação de Professores: proposições para a formação para o trabalho científico na Licenciatura em Educação Física. 2016. 363f. Tese (Doutorado em Educação) - Faculdade de Educação, Universidade Federal da Bahia, Salvador, 2016.

PIMENTA, Selma Garrido. Professor reflexivo: construindo uma crítica. In: PIMENTA, S. G.; GHEDIN, E. (Org.). Professor reflexivo no Brasil: gênese e crítica de um conceito. São Paulo: Cortez, 2010. p. 17-52.

PEREIRA, Jorge Adilson Gondim. Formação em Educação Física: discursos e a prática curricular. 2014. 170 f. Dissertação (Mestrado em Educação Física) - Faculdade de Educação Física, Universidade de Brasília, Brasília, 2014.

RIBEIRO, Iuri. Formação em Educação Física no Brasil: novas orientações legais, outras identidades profissionais? 2016. 126f. Dissertação (Mestrado em Educação) Pontifícia Universidade Católica de Goiás, Goiânia, 2016.

RODRIGUES, Raquel Cruz Freire. Formação de Professores: a Prática de Ensino no curso de Licenciatura em Educação Física com base na concepção de formação omnilateral e da Licenciatura Ampliada. 173f. Tese (Doutorado em Educação) Faculdade de Educação, Universidade Federal da Bahia, Salvador, 2014.

O estágio supervisionado no curso de Educação Física da UEFS: realidade e possibilidades. 2007. 105f. Dissertação (Mestrado em Educação) - Faculdade de Educação, Universidade Federal da Bahia, Salvador, 2007. 
ANÁLISE DA PRODUÇÃO CIENTÍFICA SOBRE FORMAÇÃO DE PROFESSORES:

Realidade e possibilidades na área da Educação Física

RODRIGUES, Roseane Cruz Freire. Contribuições da pedagogia histórico-crítica e da metodologia crítica superadora para o Projeto Político Pedagógico da Licenciatura em Educação Física da FACED/UFBA. 2014. 244f. Dissertação (Mestrado em Educação) Faculdade de Educação, Universidade Federal da Bahia, Salvador, 2014.

SANTOS JUNIOR, Cláudio de Lira. A formação de professores em Educação Física: a mediação dos parâmetros teórico-metodológicos. 2005. 194f. Tese (Doutorado em Educação) - Faculdade de Educação, Universidade Federal da Bahia, Salvador, 2005.

SAVIANI, Demerval. Escola e Democracia. 38.ed. Campinas: Autores Associados, 2006.

SILVA, Melissa Fernanda Gomes da. A prática como lócus de formação de professores e produção de saberes na Educação Física. 2014. 269f. Tese (Doutorado em Ciência da Motricidade) - Instituto de Biociências, Universidade Estadual Paulista, Rio Claro, 2014.

SOUZA, Bárbara Isabela Soares de. Currículo e formação de professores: análise dos projetos pedagógicos dos cursos de Educação Física em Goiás. 2017. 150f. Dissertação (Mestrado em Educação Física) - Faculdade de Educação Física, Universidade de Brasília, 2017.

TAFFAREL, Celi Nelza Zulke. Por uma política científica para a Educação Física com ênfase na integração Educação Básica, Graduação e Pós-Graduação. In: Congresso Sulbrasileiro de Ciências do Esporte. Santa Maria/RS, 2006.

TAFFAREL, Celi N. Z.; SANTOS JÚNIOR, Cláudio de Lira. Formação humana e formação de professores de Educação Física: para além da falsa dicotomia licenciatura $\mathrm{x}$ bacharelado. In: TERRA, D. V.; SOUZA JÚNIOR, M. (Org.). Formação em Educação Física \& Ciências do Esporte: políticas e cotidiano. São Paulo: Aderaldo \& Rothschild; Goiânia: CBCE, 2010. p.13-47.

Recebido em: 21 mar. 2020. Aprovado em: 06 jun. 2020.

\footnotetext{
* Márcia Morschbacher é professora da Universidade Federal de Santa Maria (UFSM) e coordenadora do Comitê Científico do GTT Formação Profissional e Mundo do Trabalho do Colégio Brasileiro de Ciência do Esporte (CBCE). Licenciada em Educação Física (UNOESC), é doutora em Educação (UFBA) e mestre em Educação Física (UFPEL). É pesquisadora do Grupo de Estudos e Pesquisas em Educação Física, Esporte e Lazer (LEPEL/FACED/UFBA).

E-mail: mm.edufisica@yahoo.com.br
}

https://orcid.org/0000-0003-2193-0998 
** Melina Silva Alves é professora da Universidade Federal da Paraíba (UFPB) e pesquisadora do Grupo de Estudos e Pesquisas em Educação Física, Esporte e Lazer (LEPEL/FACED/UFBA). Licenciada em Educação Física (UFPR), é doutora em Educação (UFBA) e mestre em Educação (UFS).

E-mail: melinasalves@gmail.com

https://orcid.org/0000-0002-0100-253X

*** Raquel Cruz Freire Rodrigues é professora da Universidade Estadual de Feira de Santana (UEFS), onde integra o Laboratório Multidisciplinar das Licenciaturas. Licenciada em Educação Física (UPE), possui Mestrado e Doutorado em Educação pela UFBA. É membro da diretoria nacional da ANFOPE.

E-mail: raquelrodrigues@uefs.br

https://orcid.org/0000-0002-0241-6988 